\title{
Medical students' experience with accessing medical records in Saudi Arabia: a descriptive study
}

Jwaher A. Almulhem

\begin{abstract}
Background: Medical students can enhance their knowledge by accessing patients' medical records and documenting patient care. This study assessed medical students' access to paper medical records and electronic health records (EHRs) in Saudi Arabia and compared students' experience of accessing paper medical records and EHR from their perspective.

Methods: This cross-sectional study enrolled second-year to intern medical students randomly from different medical colleges in Saudi Arabia. A self-developed survey was administered to them. It comprised 28 items in three sections: general information about medical students and their level of accessing medical records, their experience with the medical record system used in hospitals, and their preference for the medical record type.

Results: $62.8 \%$ of participants had access to medical records, with $66.1 \%$ of them having access to EHRs and 83.27\% had read-only access. The EHR group and paper group mostly liked being able to reach medical records effortlessly (70.1\% and $67.1 \%$, respectively). The EHR group had a better experience compared to the paper group with $U=5200$, Mean Rank $=122.73, P=.04$. Students who trained in University - owned and National Guard hospitals had better experiences compared to students who trained in other hospitals with Mean Ranks $=122.35$, and 147.99 , respectively.
\end{abstract}

Conclusion: Incorporating EHR access into the medical curriculum is essential for creating new educational opportunities that are not otherwise available to medical students.

Keywords: Medical students, Access to medical record, Saudi Arabia, Access to electronic health record, Medical education

\section{Background}

Medical students can improve their knowledge by accessing patients' medical records and documenting patient care [1]. With regard to learning theory, medical students' participation in documenting patient care is an educational activity [2]. Acquiring documentation skills changes depending on the number of years in medical

Correspondence: Jalmulhem@ksu.edu.sa

Medical Informatics and E-learning Unit, Medical Education Department,

College of Medicine, King Saud University, Riyadh, Kingdom of Saudi Arabia schools, starting with recording clinical data in preclinical years, followed by ranking, combining, and incorporating clinical information during clinical years. Finally, a medical student's documentation becomes a method of information exchange and communication between different health providers [3].

It is critical for medical students to have access to medical records for educational purposes. When healthcare organizations use traditional paper medical records, students did not have any barrier with accessing medical records [4] and have more opportunity in entering 
patients' orders [5]. They usually gain required skills of writing notes and entering orders as part of their clinical experience. However, transition to electronic health record (EHR) necessitate acquiring essential EHR-related competencies after graduation [6]. Medical students need to learn about several aspects of using EHRs, including recording patients' medical histories and physical examination; documenting and ordering laboratory tests, radiology, medication, and consultation care; and understanding the method of using EHRs in specific hospitals $[7,8]$. Third-year medical students spend more than $4 \mathrm{~h}$ using EHRs and write, on average, three notes in medical records per day [9].

Increasing learning experience and familiarity with EHR among future physicians, will enhance positive impact resulted from using such system. Starting with implementation phased, McGinn et al. [10] indicated familiarity and ability of using EHR is one of the facilitator factors of implementation process. Physicians who had 4 years or more experience with EHR were more likely to agree about the positive influence related to EHR use including improved patient care, data confidentiality, and reduced costs [11]. Familiarity with EHR also helps health care providers to deal with safety and maintenance issues such as hardware and software failures, wrong patient identification, and subversion of clinical decision support protocols [12]. In addition, exposure to different EHR systems implemented in hospitals will enhance medical students' experience of training and use of these systems with different features and user interfaces [13].

Duke, Frankel, and Reis [14] reported that providing full medical record access to medical students is important as it will help them understand how to extract and retrieve patients' medical histories and other significant information. Specifically, medical students need to use clinical decision support systems (CDSS) and computerized physician order entries so that they can use these systems when providing medical care in the future. Biagioli et al. [15] linked a lack of proper EHR training to skill deficiencies in several EHR-related core aspects such as medical history review, medication reconciliation, and allergy reconciliation. In addition, most medical students' EHR skills do not improve as the year proceeds, if they do not acquire these skills in their early undergraduate medical years. Providing medical students access to EHRs will help them track patients and record medical procedures, improve self-directed learning, and increase their understanding of diagnostic and prognostic consequences [16, 17].

Hammoud et al. [18] conducted a national survey of clerkship directors to explore the current practice of the use of EHRs among US medical students. They found that only $64 \%$ of surveyed programs allow medical students to use EHRs, with two-thirds of them allowed to view EHRs, write notes, and enter orders. The Liaison Committee on Medical Education (LCME) reported that the level of access differs across different types of hospitals. In addition, $\sim 30 \%$ of University-owned hospitals allow medical students to view EHRs without entering or modifying patient information $[6,19]$. The percentage of medical students who access EHRs has increased from 78 to $93 \%$, while the mean percentage of clerkships in which a medical student uses paper medical records has decreased over time [20].

With transferring from paper medical record to EHR [6], hospitals restrict medical students access to EHRs for several reasons. In the LCME Annual Medical School Questionnaire Part II, 45 of 140 hospitals indicated that the main reason for preventing medical students from entering information into the EHR system is hospital and/or medical staff requirements and another reason is the EHR system structure [6]. Financial aspects related to providing medical students with computers, EHR licenses, and authorization cardinals to access various systems also play a role in access restriction [18]. In addition, hospitals might implement policies that restrict documentation by medical students in order to avoid regulatory issues, such as Joint Commission citations for use of incorrect abbreviations [3].

The Saudi Medical Education Directives (SaudiMED) requires several learning outcomes and competencies that are anticipated by medical students after their graduation. The framework specified two program learning objectives (PLOs) that related to accessing patient records; communicate with health professionals and patients effectively and use medical informatics systems appropriately during providing healthcare. They elaborate on these PLOs with specific enabling competencies that should be met by medical students before beginning their internship program. Effective communication involves using verbal and documenting skills to disseminate medical information. Using the medical informatics system appropriately through storing, retrieving information, and using this information ethically in providing patient care and health promotion [21].

The Ministry of Health (MOH) launched an E-Health strategy that depends on several dimensions such as patient-centric care and interoperable EHR [22]. A recent study found the attitude towards E-health use was positive among medical students [23]. Indeed, authentic of clinical experiences, which included documenting in patients' records, was mentioned as a factor for improving Saudi medical students learning environment [24]. $\mathrm{MOH}$ stated that "By 2020: $70 \%$ of the population will have digitized unified health records" [25]. A recent study found that most of the medical students favored a reasonable amount of technology in their education. 
They concluded that the cooperation of information technology (IT) with the curriculum is required to increase the utilization of available resources [26]. Consequently, involving EHR competences in medical students' curriculum is one of the essential steps to prepare future medical professionals in Saudi Arabia.

Yet, this is the first study in Saudi Arabia to discuss this topic among medical students and understand the educational impact of accessing medical records among medical students from several medical universities and different clinical sittings. Indeed, prior studies focus on impact of medical record in one specialty or individual clinical sitting [27, 28]. Recognizing actual students' viewpoint regrading accessing medical record and their educational impact have not been extensively reported from students since previous studies depend on medical educators' point of view $[18,29]$. Furthermore, comparing learning experience between students who access traditional paper record and EHR is not clear yet and have not extensively studied in the literature [5]. Accordingly, this study assessed medical students' access to paper medical records and EHR in Saudi Arabia and compared the experience of accessing paper medical records and EHR from the medical students' perspective.

Improving understanding of medical record's educational benefits will encourage medical educators to involve already implemented IT systems in healthcare organizations to enhance the medical education environment since using EHR is compulsory during these days. Recognizing barriers that prevent medical students access to medical record, particularly after shift from paper medical records to EHR, will help academic institutions to be aware of students' current educational environment and recommend possible solutions.

\section{Methods}

\section{Study design and the sample}

This descriptive, cross-sectional study was conducted with second-year to intern medical students. The number of medical colleges is approximately 31 colleges in Saudi Arabia [30]. Before the communication process, We randomly selected 10 universities and sent a formal letter from the postgraduate and scientific research deanship in King Saud University to the postgraduate and scientific research deanship of these universities. The purpose of these letters is to introduce the researcher and the purpose of this study. Also, it involved asking for permission and facilitation of data collection process among medical students. Only 4 of 10 universities responded.

The study was approved by the King Saud University ethical committee (KSU-KSU-HE-19-374).

\section{Instrument development and distribution}

A self-developed survey was designed after reviewing several studies on medical students' access to medical records $[6,19,28,31]$. The survey was developed using the Google Form Survey development tool. Several experts in health informatics, medical education and former medical students reviewed the survey before distribution. According to their suggestions, sequence of the questions and few wording issues of the first draft were identified and corrected before distribution.

Next, the survey was distributed through the medical colleges' official email, learning management systems, and other formal student groups. To increase the response rate, a second reminder over the medical students' official email was sent. The data collection started in 3/3/2019 and lasted for 12 months. The required sample size was 384, calculated on the basis of the Kotrlik and Higgins formula [32]. The email also included the study's objectives and a link to participate voluntarily and anonymously. Finally, 388 medical students participated in the study.

The survey comprised 28 items in three sections (see the Additional file 1): (i) general information about the medical students and their level of accessing medical records, (ii) their experience with the medical record system used in hospitals, and (iii) their preference regarding the medical record type they wanted to use in their future practice. Section 1 asked about the medical students' age, gender, studying year, hospital type, access to medical records (yes/no), access method (free to access, access from IT team, access through a senior's account, other), type of medical record (paper medical record, EHR), and level of access (read-only, full access). (Having full access means being able to read, review, and enter order/data in the medical record.) To understand the reason behind medical student access restriction, we asked those who did not have access to specify the reason for restriction (hospital policy, liability concerns, difficulty of the medical record system, medical staff instructions, other). In addition, we asked those who had full access about their documentation skills (patient history, physical examination, medication and investigation orders, and documentation completeness).

Section 2 asked about medical record access experience and patient relationships while using medical records, including finding medical records, finding medical information, asking more questions, maintaining eye contact with the patient, time spent with the patient, and doctor-patient communication. The responses used a 5-point Likert scale from "strongly agree" to "strongly disagree."

Section 3 asked about the medical students' choice between paper medical records and EHRs with regard to taking the patients' medical histories, performing 
physical examination, entering orders, accessing clinical guidelines, and organizing information. At the end of this section we asked the participants to explain why they preferred the selected type of medical record in an open-ended question format. In addition, there were two extra open-ended questions about any further educational impact of medical records and the medical students' experience in other hospitals if they worked in more than one.

The reliability of instrument was calculated based on Cronbach's alpha. The alpha values were measured for full access items, medical record access experience items, and preferences items. The value achieved were .676 , .558 , and .834 , respectively, indicating a satisfactory level of reliability [33].

\section{Data analyses}

Data were analyzed using SPSS Statistics v.19 (IBM Corporation, Armonk, NY, USA). Descriptive statistics for demographic data, level of access, experience, and preference was calculated. The experience with accessing medical records which differed depending on the type of medical record was presented through calculating median and interquartile range (IQR). 5-point Likert scale questions ' responses were combined into three categories: disagree (1) (combining "strongly disagree" and "disagree"), neutral (2), and agree (3) (combining "strongly agree" and "agree"). Open-ended questions were analyzed using thematic analysis including reviewing and extracting themes, as suggested by Popping [34]. To compare students' experiences between paper medical records and EHRs, Mann-Whitney U and KruskalWallis tests were performed. Significance was assessed at the 0.05 level.

To address non-response bias, several methods were recommended such as comparing results with population's characteristics and wave analysis. The second method was selected due to availability of survey data. It involves comparing results of main study's variable between early responders and late responders. Early responders are considered as responders and late responders are similar to non-responders $[35,36]$. The mean response of access experience items between these two groups were compared. The analysis suggested that there is no significant differences between the early responders and late responders at the 0.05 level. Accordingly, there are no significant differences between responders and non-responders. This result increases the confidence that the sample group is representative to the population group.

\section{Results}

The total number of students who received the email is 2400 students and 388 responded, which resulted in
$16.1 \%$ response rate. Of the 388 participants, 17 were excluded since they did not practice in hospitals. Therefore, 371 completed surveys were included in the study. Table 1 shows their characteristics. The majority of participants were female (68.5\%) aged $18-23$ years (71.4\%). In addition, $103(27.8 \%)$ of participants were in the fourth year, with 246 (66.3\%) of them training in University-owned hospitals; 138 (37.2\%) did not have access to medical records; and $56.5 \%$ of the 138 participants were restricted by hospital policy (Fig. 1).

With regard to access to medical records, 81 (34.8\%) of the participants had access through a senior's account. More than half $(66.1 \%)$ had access to the EHR system, and the majority $(83.27 \%)$ had only read-only access (Table 2).

The experience with accessing medical records differed depending on the type of medical record (Table 3). Median was used to report participants' experiences. Median of all experience items were 3 among paper group. They mostly agree on reaching medical records without effort (67.1\%) followed by satisfaction with the

Table 1 Characteristics of participants

\begin{tabular}{|c|c|c|}
\hline Characteristics & $n(371)$ & (\%) \\
\hline \multicolumn{3}{|l|}{ Gender } \\
\hline Male & 117 & 31.5 \\
\hline Female & 254 & 68.5 \\
\hline \multicolumn{3}{|l|}{ Age } \\
\hline $18-23$ & 265 & 71.4 \\
\hline $24-28$ & 96 & 25.9 \\
\hline$>28$ & 10 & 2.7 \\
\hline \multicolumn{3}{|l|}{ Year } \\
\hline Second-year & 31 & 8.4 \\
\hline Third-year & 46 & 12.4 \\
\hline Fourth year & 103 & 27.8 \\
\hline Fifth year & 43 & 11.6 \\
\hline Sixth year & 76 & 20.5 \\
\hline Intern & 72 & 19.4 \\
\hline \multicolumn{3}{|l|}{ Type of hospital } \\
\hline University-owned hospital & 246 & 66.3 \\
\hline Ministry of Health hospital & 82 & 22.1 \\
\hline Private hospital & 5 & 1.3 \\
\hline National Guard Hospital & 12 & 3.2 \\
\hline Armed Forces Hospital & 9 & 2.4 \\
\hline Security Forces Hospital & 2 & 0.5 \\
\hline Others & 15 & 4.2 \\
\hline \multicolumn{3}{|c|}{ Having access to medical record } \\
\hline Yes & 233 & 62.8 \\
\hline No & 138 & 37.2 \\
\hline
\end{tabular}




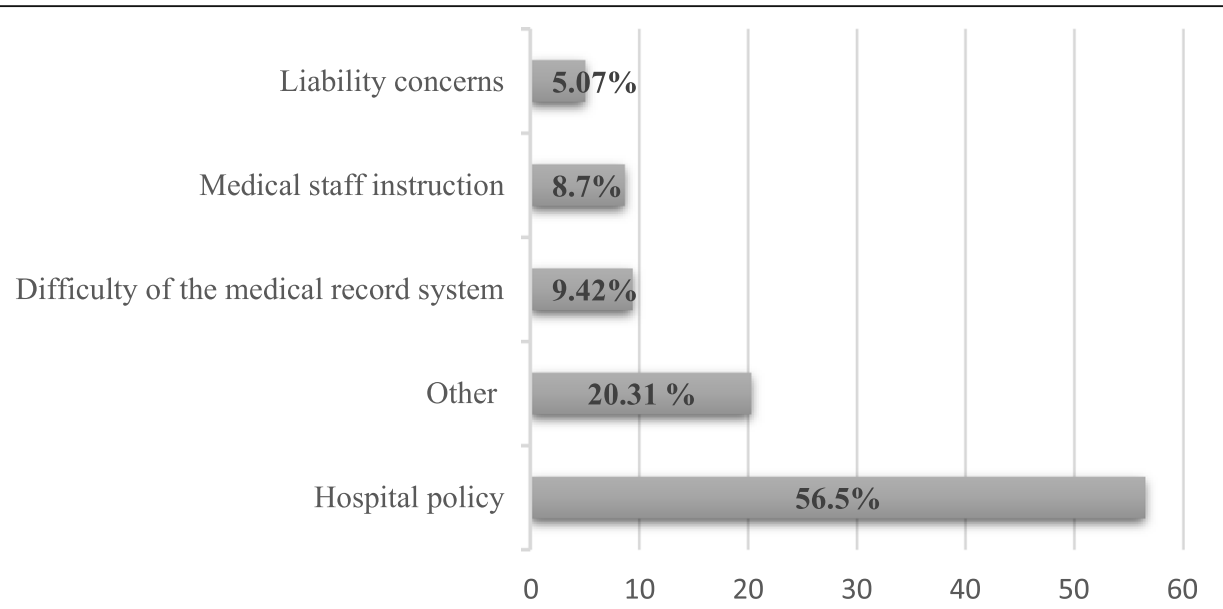

Fig. 1 Reasons for restricting participants' access to medical records

doctor-patient communication while using medical records (51.9\%). Median of all items were 3 among EHR group expect for eye contact time with patients and spending time with patient, which were 2 . EHR group mostly liked reaching medical records easily $(70.1 \%)$ and mostly disagree about positive impact of using EHR on the eye contact time with patients (37.0\%).

Fig. 2 presents the benefits of providing full medical record access to medical students. Precise writing of patient history was the mostly agreed-on outcome (89.7\%), followed by correct writing of physical examination $(87.2 \%)$, completeness of documentation $(79.5 \%)$ and ordering (51.3\%).

Fig. 3 shows each group's preference for the type of medical record. The majority $(86.7 \%)$ would like to use EHRs in their future practice, In addition, $90.1 \%$ of participants preferred using EHRs to enter orders, while only $9.9 \%$ preferred using paper medical records to enter orders, and $86.3 \%$ preferred the organization of information in EHRs. Interestingly, $36.1 \%$ and $37.3 \%$ of

Table 2 Access methods, type of medical record, and level of access provided to participants who accessed to medical record

\begin{tabular}{lll}
\hline Variable & $\boldsymbol{n}$ (233) & \% \\
\hline Access methods & 67 & 28.8 \\
Free to access & 59 & 25.1 \\
Access from IT team & 81 & 34.8 \\
Access through a senior account & 26 & 11.3 \\
Other & & \\
Type of medical record & 79 & 33.9 \\
Paper medical record & 154 & 66.1 \\
$\quad$ Electronic health record & & \\
level of access & 194 & 83.27 \\
$\quad$ Read- only access & 39 & 16.73 \\
Full access (read, review and enter order/data) & 39 \\
\hline
\end{tabular}

participants liked paper medical records for taking a medical history and performing a physical examination, respectively.

Mann-Whitney $U$ test was performed to test the effects of gender, type of medical record, and level of access on the experience with accessing medical records (Table 4). There was no significant difference in experience between males and females and between participants who had full access compared to those who had read-only access. There was a significant difference between experiences with the type of medical record $(U=$ 5200, $P=.04$ ). The EHR group had a better experience compared to the paper group.

Kruskal-Wallis test compared the effect of age, type of hospital, and studying year on the participants' experience with using medical records (Table 5). There were statistically significant differences in experience with using medical records based on the type of hospital $\left(x^{2}=\right.$ 12.684, $P=.048)$. To know which of the specific groups differed, Mann-Whitney test was performed. Results showed significant differences at the. 05 between participants in University-owned hospitals and Ministry of Health hospitals to University-owned hospitals (Mean Rank =122.35). Also, Significant differences between Ministry of Health hospitals and National Guard Hospitals to National Guard Hospital (Mean Rank =147.90).

\section{Open-ended questions}

The survey included three open-ended questions. In regard to reason of preference, most of the responses were from participants who preferred EHRs, and only a few answers were from participants who preferred paper medical records. In addition, one participant liked to organize ideas on paper. The participants stated several benefits of EHRs, and five categories emerged:

Category 1: legibility and clarity. 
Table 3 Participants' experience with accessing medical records

\begin{tabular}{|c|c|c|c|c|c|c|c|c|c|c|}
\hline \multirow[t]{2}{*}{ Experience with medical records } & \multicolumn{5}{|c|}{ Paper medical record $(n=79)$} & \multicolumn{5}{|c|}{ EHR $(n=154)$} \\
\hline & $\begin{array}{l}\text { Disagree } \\
n(\%)\end{array}$ & $\begin{array}{l}\text { n } \\
\text { Neutral } \\
n(\%)\end{array}$ & $\begin{array}{l}\text { Agree } \\
n(\%)\end{array}$ & Median & $\mathrm{IQR}$ & $\begin{array}{l}\text { Disagree } \\
\mathrm{n}(\%)\end{array}$ & $\begin{array}{l}\text { Neutral } \\
\text { n (\%) }\end{array}$ & $\begin{array}{l}\text { Agree } \\
\text { n (\%) }\end{array}$ & Median & IQR \\
\hline It was easy to reach medical records & $12(15.2)$ & $\begin{array}{l}14 \\
(17.7)\end{array}$ & $\begin{array}{l}53 \\
(67.1)\end{array}$ & 3 & 1 & $\begin{array}{l}23 \\
(14.9)\end{array}$ & $\begin{array}{l}23 \\
(14.9)\end{array}$ & $\begin{array}{l}108 \\
(70.1)\end{array}$ & 3 & 1 \\
\hline $\begin{array}{l}\text { It was easy to find essential information (e.g. past } \\
\text { medical history and medications) }\end{array}$ & $25(31.6)$ & $\begin{array}{l}22 \\
(27.8)\end{array}$ & $\begin{array}{l}32 \\
(40.5)\end{array}$ & 3 & 2 & $25(16.2)$ & $27(17.5)$ & $\begin{array}{l}102 \\
(66.2)\end{array}$ & 3 & 1 \\
\hline $\begin{array}{l}\text { The items of medical records encouraged me to ask } \\
\text { more history/physical examination questions }\end{array}$ & $9(11.4)$ & $\begin{array}{l}30 \\
(38.0)\end{array}$ & $\begin{array}{l}40 \\
(50.6)\end{array}$ & 3 & 1 & $19(12.3)$ & $37(24.0)$ & $\begin{array}{l}98 \\
(63.6)\end{array}$ & 3 & 1 \\
\hline $\begin{array}{l}\text { Using medical records (read /data entry) affected } \\
\text { positively on the eye contact time with patients }\end{array}$ & $15(19.0)$ & $\begin{array}{l}37 \\
(46.8)\end{array}$ & $\begin{array}{l}27 \\
(34.2)\end{array}$ & 3 & 1 & $57(37.0)$ & $44(28.6)$ & $\begin{array}{l}53 \\
(34.4)\end{array}$ & 2 & 2 \\
\hline $\begin{array}{l}\text { Using medical records (read/data entry) affected } \\
\text { positively on the time that should be spent with } \\
\text { patients }\end{array}$ & $25(31.6)$ & $\begin{array}{l}31 \\
(39.2)\end{array}$ & $\begin{array}{l}23 \\
(29.1)\end{array}$ & 3 & 2 & $54(35.1)$ & $38(24.7)$ & $\begin{array}{l}62 \\
(40.3)\end{array}$ & 2 & 2 \\
\hline $\begin{array}{l}\text { Overall, I was satisfied with the doctor-patient } \\
\text { communication while using medical records }\end{array}$ & $8(10.1)$ & $\begin{array}{l}30 \\
(38.0)\end{array}$ & $\begin{array}{l}41 \\
(51.9)\end{array}$ & 3 & 1 & $15(9.7)$ & $40(26.0)$ & $\begin{array}{l}99 \\
(64.3)\end{array}$ & 3 & 2 \\
\hline
\end{tabular}

$I Q R$ interquartile range

Category 2: accessibility and availability,

Category 3: data entry and organization,

Category 4: safety and privacy.

Category 5: secondary uses of EHR data, such as

medical research.

In reference to working in different hospitals, the majority described an unsatisfactory experience with paper medical records because of difficulty in reading and finding information, incompleteness, and disorganization. In contrast, many participants were satisfied with using EHRs, including access and a comprehensive view of patient data. However, a few were disappointed with EHRs because of difficulty in learning, slowness, a lack of features, and inappropriate access. In addition, few participants stated they had a good experience with paper medical records related to easy information access.
Many participants asked for access to medical records and to be trained on how to review and write in medical records before internship. Several participants wanted to acquire skills related to writing in medical records, even as a mock-up model or under their seniors' supervision, which would help them in their future practice. With regard to educational benefits of medical records, many participants clarified the role of EHRs in directing medical students' history taking and physical examination as EHRs include all essential information. One participant also suggested considering long cases from medical records as teaching materials that could be incorporated into the medical curriculum.

\section{Discussion}

Medical students in Saudi Arabia require competencies in using medical informatics applications and medical information documentation before graduation [21]. To

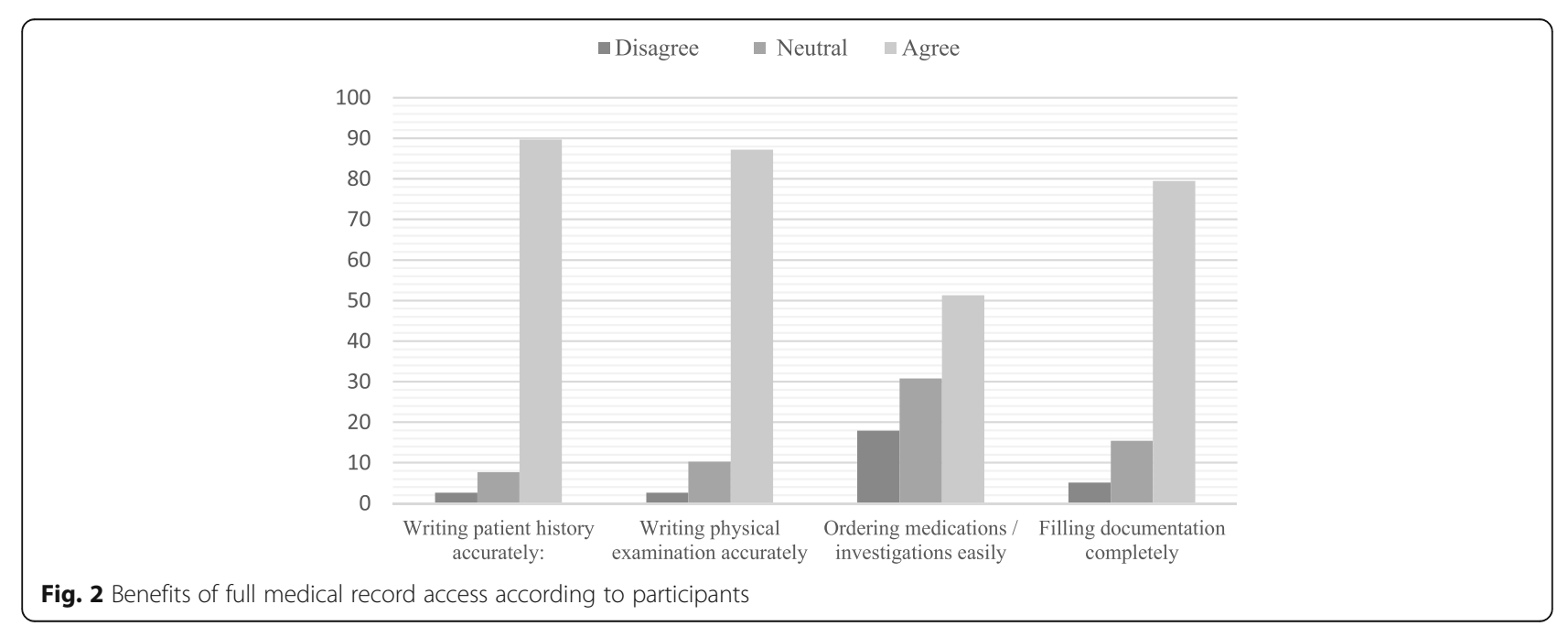




$$
\begin{aligned}
& \text { In general, I prefer using----------- during } \\
& \text { my practice } \\
& \text { Structure of the medical records } \\
& \text { (Organization of information): }
\end{aligned}
$$

Accessing clinical guidelines (e.g. blood pressure guidelines):

Entering orders

(labs/imagines/medications):

Performing physical exam by using

Taking patient history through:

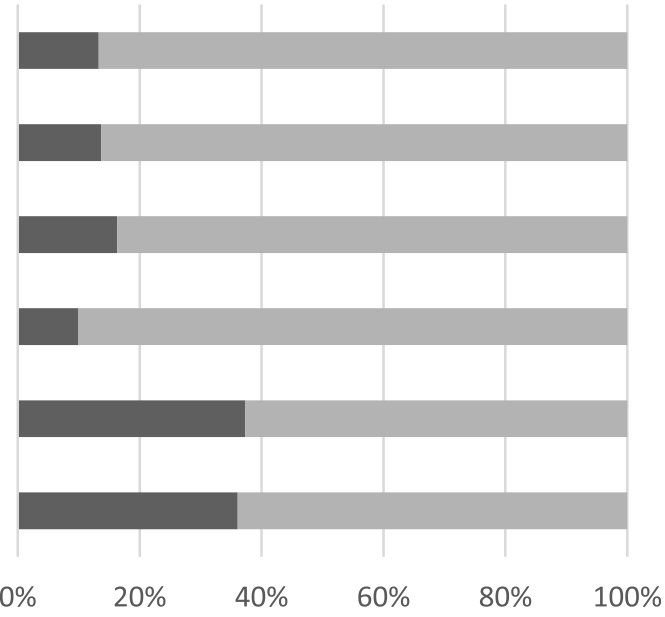

- Paper-based medical record

$\square$ Electronic medical record

Fig. 3 Participants' preference for the type of medical record they want to use in their future practice

our knowledge, no studies have investigated medical students accessing medical records in Saudi Arabia that involves student perspectives, different academic institutions and comparing learning experience between EHR and paper medical records. This descriptive study examined medical students' access to paper medical records and EHRs in Saudi Arabia and compared the experience of accessing paper medical records and EHR from the medical students' perspective.

Most medical students had access to medical records, which is consistent with the results of Welcher et al. [6], who reported that $96 \%$ of medical schools allow students to access medical records. Not surprisingly, most of the medical students in this study accessed EHRs compared to paper medical records, which is similar to other studies [27, 37]. This is an indication of minimal use of paper medical records in Saudi Arabia's hospitals.

One of the factors that effects on students' experience is the type of institution. The University owned and
National Guard hospitals provide a better experience for medical students. The reason maight be that these hospitals give medical students more opportunities to interact with patient and medical records compared to other types of hospitals. In fact, most of University-owned hospitals provided full access to medical students during 2013-2014 [6].

In this study, hospital policies are the biggest reason for restricting medical students' access to medical records, which is consistent with the results of Wittels et al. [38]. Having hospital policies as a main barrier for accessing medical record may indicate hospitals concerns related to liability. Liability concerns could raise if students have ability to document in EHR, which is reported as second barrier [38]. A possible solution of this issue is providing feedback to medical students after documentation which enhance documentation skills [38]. This finding also explained why most medical stu-

\begin{tabular}{|c|c|c|c|c|c|}
\hline Characteristics & $n(233)$ & Mean Rank & Sum of Ranks & Mann-Whitney U & P-value \\
\hline \multicolumn{6}{|l|}{ Gender } \\
\hline Male & 75 & 120.48 & 9036 & 5664 & .55 \\
\hline Female & 158 & 115.35 & 18,225 & & \\
\hline \multicolumn{6}{|l|}{ Type of record } \\
\hline Paper medical record & 79 & 105.82 & 8360 & 5200 & .04 \\
\hline Electronic medical record & 154 & 122.73 & 18,901 & & \\
\hline \multicolumn{6}{|l|}{ Level of access } \\
\hline Read-only only access & 194 & 116.18 & $22,539.50$ & 3624.50 & .65 \\
\hline Full access & 39 & 121.06 & 4721.50 & & \\
\hline
\end{tabular}
dents who have access to medical records use seniors'

Table 4 Effect of participants' gender, type of medical record, and level of access on their experience with accessing medical records 
Table 5 Effect of participants' age, type of hospital, and studying year on their experience with accessing medical records

\begin{tabular}{|c|c|c|c|c|}
\hline Characteristics & n (233) & Mean Rank & $x^{2}$ & $P$-value \\
\hline \multicolumn{5}{|l|}{ Age } \\
\hline $18-23$ & 139 & 115.90 & 2.50 & .286 \\
\hline $24-28$ & 84 & 122 & & \\
\hline$>28$ & 10 & 90.30 & & \\
\hline \multicolumn{5}{|l|}{ Type of hospital } \\
\hline University-owned hospital & 142 & 122.35 & 12.68 & .048 \\
\hline Ministry of Health hospital & 57 & 98.48 & & \\
\hline Private hospital & 5 & 76.00 & & \\
\hline National Guard Hospital & 10 & 147.90 & & \\
\hline Armed Forces Hospital & 7 & 118.79 & & \\
\hline Security Forces Hospital & 2 & 169.00 & & \\
\hline Others & 10 & 124.60 & & \\
\hline \multicolumn{5}{|l|}{ Studying year } \\
\hline Second-year & 8 & 50.06 & 11.01 & .051 \\
\hline Third-year & 9 & 110.78 & & \\
\hline Fourth year & 50 & 123.69 & & \\
\hline Fifth year & 33 & 112.09 & & \\
\hline Sixth year & 68 & 122.49 & & \\
\hline Intern & 65 & 117.71 & & \\
\hline
\end{tabular}

$x^{2}$ (Chi-Square)

accounts, which also mentioned by other study [39]. Beside liability concerns, other studies mentioned other barriers such as billing, reduced productivity, financial concerns, and logistical and structural problems $[3,6$, 18]. Regarding financial barrier, the annual license fee ranges from $\$ 800$ to $\$ 3200$ per provider. This cost did not include maintenance, hardware, and productivity loss fees [40].

Providing full access of medical record to medical students is necessary as appropriately using EHRs is an important competency that affects patient care and safety [31], as well as increasing EHR familiarity will enhance positive impact resulted from using EHR [11, 12]. Most education deans have reported that medical students' education would be undesirably affected without involving them in documentation [29]. In fact, many participants stated the importance of providing EHR access to medical students and recommend methods for such access in the open-ended questions.

This study confirmed that medical students who access EHRs had a better experience than those who access paper medical records. Furthermore, most medical students are satisfied with reaching medical records easily and finding essential information while using EHRs. With regard to preference, most of the participants in this study liked the organization of information and access to medical guidelines in EHRs. One study found that most medical students enjoy the ability of EHRs to organize information [28]. In addition, EHRs have the advantage of promoting medical students to ask more questions related to medical history [28], which was also confirmed in this study. However, integrating EHR with medical education led to several disadvantages that may influence on educational outcomes. Using of EHR template and "copy and paste" feature may affect negatively on students' critical thinking and synthesizing information. Patient - doctor communication may also negatively affect with using EHR [18, 28]. Although, most students prefer using EHRs in their future practice, the main question remains whether paper record offer students all the clinical educational benefits that could be acquired from EHR. In fact, students who accessed paper medical record mostly liked ability to access medical record effortlessly and ability to write more orders [5]. However, current transformation to EHR requires additional skills that not required from students when using traditional paper records like electronic ordering and using of CDSS $[7,8]$. Such question needs to be discussed extensively in literature.

Although the SaudiMED framework requires medical students to acquire writing skills and use informatics systems effectively before graduation [21], the majority of participants had read-only access in this study. However, other studies that found that most medical schools allow medical students to write on patients' records $[6,27,37]$. In fact, in this study, participants who had full access (read, review, and enter order/data) mostly agreed on the educational benefits of medical records, such as accurate writing of a patient's medical history and physical examination. Therefore, medical students who do not have such experience might miss acquiring and practicing some of these fundamental skills which required by medical graduate students [20, 21].

To ensure proper access of EHRs to medical students, several regulations and hospital policies need to be implemented and proper EHR training incorporated into the medical curriculum. In fact, several organizations recommended principles to support such educational opportunities $[4,19,41]$. In this study, although the participants had access to medical records, their responses to the open-ended questions revealed the necessity of proper control of such access as access accounts had been freely distributed among them and most had access through their seniors' accounts. Medical students should be provided proper EHR training before proving them access to medical records as it will help them practice and use EHR systems easily. In this study, many participants also disliked the use of the EHR system because of the 
difficulty of learning and slowness, which may increase the resistance to EHR and minimize the value of using EHRs in their future practice. King Saud University provide such training for third year medical students as a part of medical informatics course.

This study had several limitations. First, it described medical students' experiences by using a survey. Experiences might vary depending on the type of system used and training hospitals. The actual usage of EHRs was not measured. However, several studies have used surveys as a tool to understand medical students' experience with using medical records and their impact on education $[18,20,42]$. Future research may depend on actual user data that can be extracted from EHR systems and reflect actual usage. Second, the survey used was self-developed and was not validated, although it was based on several studies that discussed medical students' access to medical records [6, $28,31]$ and was reviewed by several experts prior to distribution. The small sample size is a limitation since the number of the completed survey was less than the required due to removal of 17 surveys. However, the number of students who returned the survey achieved the required sample size. Another limitation is the low response rate, even though several strategies were used to boost the response rate including sending reminders after 2 weeks, adding the survey link in the email, ensuring anonymity of respondents, and extending survey availability [43]. Indeed, webbased respond rate has lower response rate compared to paper-based survey [43]. Future work can explore if paper medical record provide more educational benefits compared to EHR. In addition, it can discover medical school policies and training related to medical students' access to medical records in Saudi Arabia.

\section{Conclusion}

Accessing medical records helps medical students acquire several fundamental skills for their future practice. Medical students' experience with EHRs is better compared to paper medical records. Providing read-only access restricts medical students' educational experience. Incorporating EHR access into the medical curriculum is essential as it will provide new educational opportunities that were not available before.

\footnotetext{
Abbreviations

EHR: Electronic health record; CDSS: Clinical decision support systems; IT: Information technology; LCME: Liaison Committee on Medical Education; SaudiMED: Saudi Medical Education Directives; PLO: Program learning objective; $\mathrm{MOH}$ : Ministry of Health; IQR: Interquartile range; $x^{2}$ : Chi-Square
}

\section{Supplementary Information}

The online version contains supplementary material available at https://doi. org/10.1186/s12909-021-02715-7.

\section{Additional file 1.}

\section{Acknowledgements}

The author would like to thank medical colleges which allowed their students to participate in the study. I thank medical informatics experts, Dr. Bashier Almulhem, and Dr. Mannahel Almulhem who reviewed the survey before distribution. Furthermore, the author thanks the Deanship of Scientific Research and RSSU at King Saud University for their technical support.

\section{Author's contributions}

JA was the author in conducting the study and writing the manuscript. The author(s) read and approved the final manuscript.

\section{Funding}

Not applicable.

\section{Availability of data and materials}

The analysed data used during the study are available from the corresponding author on reasonable request.

\section{Declarations}

Ethics approval and consent to participate

The ethical approval was obtained from King Saud University ethical committee (KSU-KSU-HE-19-374). All protocols are carried out in accordance with relevant guidelines and regulations. All the participants voluntarily participated in this study and provided written informed consent. Medical colleges granted permission for their students to be involved in this study.

\section{Consent for publication}

Not applicable.

\section{Competing interests}

The author declares that there are no competing interests.

Received: 1 October 2020 Accepted: 28 April 2021

Published online: 12 May 2021

\section{References}

1. Shortliffe EH, Shortliffe EH, Cimino JJ, Cimino JJ. Biomedical informatics: computer applications in health care and biomedicine: Springer; 2014. https://doi.org/10.1007/978-1-4471-4474-8.

2. Mann KV. The role of educational theory in continuing medical education: has it helped us? J Contin Educ Heal Prof. 2004;24(S1):S22-30. https://doi. org/10.1002/chp.1340240505

3. Gliatto P. Masters P, Karani R. Medical student documentation in the medical record: is it a liability? Mount Sinai J Med. 2009;76(4):357-64. https://doi.org/10.1002/msj.20130.

4. Hammoud MM, Dalrymple JL, Christner JG, Stewart RA, Fisher J, Margo K, et al. Medical student documentation in electronic health records: a collaborative statement from the Alliance for clinical education. Teach Learn Med. 2012;24(3):257-66. https://doi.org/10.1080/10401334.2012.692284.

5. Knight AM, Kravet SJ, Harper GM, Leff B. The effect of computerized provider order entry on medical student clerkship experiences. J Am Med Inform Assoc. 2005;12(5):554-60. https://doi.org/10.1197/jamia.M1839.

6. Welcher CM, Hersh W, Takesue B, Stagg Elliott V, Hawkins RE. Barriers to medical students' electronic health record access can impede their preparedness for practice. Acad Med. 2018;93(1):48-53. https://doi.org/10.1 097/ACM.0000000000001829.

7. Matson C, Stephens M, Steiner B, Kozakowski SM. No title. Electronic Health Records: How will students learn if they can't practice? 2014.

8. Stephens MB, Gimbel RW, Pangaro L. Commentary: the RIME/EMR scheme: an educational approach to clinical documentation in electronic medical records. Acad Med. 2011;86(1):11-4. https://doi.org/10.1097/ACM.0b013e31 $81 f f 7271$

9. Chi J, Bentley J, Kugler J, Chen JH. How are medical students using the electronic health record (EHR)?: an analysis of EHR use on an inpatient medicine rotation. PLoS One. 2019;14(8):e0221300. https://doi.org/10.1371/ journal.pone.0221300. 
10. McGinn CA, Grenier S, Duplantie J, Shaw N, Sicotte C, Mathieu L, et al. Comparison of user groups' perspectives of barriers and facilitators to implementing electronic health records: a systematic review. BMC Med. 2011;9(1):1-10

11. Jamoom EW, Heisey-Grove D, Yang N, Scanlon P. Physician opinions about EHR use by EHR experience and by whether the practice had optimized its EHR use. J Health Med Informatics. 2016;7:4

12. Menon S, Singh H, Meyer AN, Belmont E, Sittig DF. Electronic health recordrelated safety concerns: a cross-sectional survey. J Healthcare Risk Manag. 2014;34(1):14-26. https://doi.org/10.1002/jhrm.21146.

13. March CA, Steiger D, Scholl G, Mohan V, Hersh WR, Gold JA. Use of simulation to assess electronic health record safety in the intensive care unit: a pilot study. BMJ Open. 2013;3:4.

14. Duke P, Frankel RM, Reis S. How to integrate the electronic health record and patient-centered communication into the medical visit: a skills-based approach. Teach Learn Med. 2013;25(4):358-65. https://doi.org/10.1080/104 01334.2013.827981.

15. Biagioli FE, Elliot DL, Palmer RT, Graichen CC, Rdesinski RE, Kumar KA, et al. The electronic health record objective structured clinical examination: assessing student competency in patient interactions while using the electronic health record. Acad Med. 2017;92(1):87-91. https://doi.org/10.1 097/ACM.0000000000001276

16. Adibe BA, Jain SH. Electronic health records: potential to transform medical education. Am J Manag Care. 2010;16:SP62.

17. Brisson GE, Neely KJ, Tyler PD, Barnard C. Should medical students track former patients in the electronic health record? An emerging ethical conflict. Acad Med. 2015;90(8):1020-4. https://doi.org/10.1097/ACM. 0000000000000633.

18. Hammoud MM, Margo K, Christner JG, Fisher J, Fischer SH, Pangaro LN. Opportunities and challenges in integrating electronic health records into undergraduate medical education: a national survey of clerkship directors. Teach Learn Med. 2012;24(3):219-24. https://doi.org/10.1080/10401334.2012. 692267

19. Association of American Medical Colleges. Level of Medical Student Access to Electronic Health Record (EHR) System. 2014; Available at: www.aamc org/data-reports/curriculum-reports/interactive-data/ehr-system-use-medica l-students, 2020

20. Foster LM, Cuddy MM, Swanson DB, Holtzman KZ, Hammoud MM, Wallach PM. Medical student use of electronic and paper health records during inpatient clinical clerkships: results of a national longitudinal study. Acad Med. 2018;93(11S):S14-20. https://doi.org/10.1097/ACM.0000000000002376.

21. Education and Training Evaluation Commission. SaudiMED Framework. 2017; Available at: etec.gov.sa/en/productsandservices/NCAAA/Accredita tionProgrammatic/Pages/Medical-Colleges.aspx, 2020.

22. National E- Health Strategy. Ministry Vision "e-Health. Available at: www. moh.gov.sa/en/Ministry/nehs/Pages/default.aspx, 2020.

23. Aldebasi B, Alhassan Al, Al-Nasser S, Abolfotouh MA. Level of awareness of Saudi medical students of the internet-based health-related information seeking and developing to support health services. BMC Med Informatics Decision Making. 2020;20(1):1-8.

24. AlHaqwi Al, van der Molen, Henk T, Schmidt HG, Magzoub ME. Determinants of effective clinical learning: a student and teacher perspective in Saudi Arabia. Educ Health 2010;23(2):369.

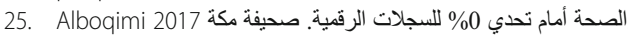

26. Khamis N, Aljumaiah $\mathrm{R}$, Alhumaid A, Alraheem H, Alkadi D, Koppel C, et al. Undergraduate medical students' perspectives of skills, uses and preferences of information technology in medical education: A cross-sectional study in a Saudi Medical College. Med Teach. 2018;40(sup1):S68-76.

27. Wallach PM, Foster LM, Cuddy MM, Hammoud MM, Holtzman KZ, Swanson DB. Electronic health record use in internal medicine clerkships and subinternships for medical students graduating from 2012 to 2016. J Gen Intern Med. 2019;34(5):705-11. https://doi.org/10.1007/s11606-019-04902-1.

28. Rouf E, Chumley HS, Dobbie AE. Electronic health records in outpatient clinics: perspectives of third year medical students. BMC Med Education. 2008;8(1):1-7.

29. Friedman $E$, Sainte $M$, Fallar R. Taking note of the perceived value and impact of medical student chart documentation on education and patient care. Acad Med. 2010;85(9):1440-4. https://doi.org/10.1097/ACM.0b013e3181 eacle0.

30. Ministry of Education. Number of Medical Colleges. Available at: https:// departments.moe.gov.sa/Pages/Default.aspx, 2020.
31. Solarte I, Könings KD. Discrepancies between perceptions of students and deans regarding the consequences of restricting students' use of electronic medical records on quality of medical education. BMC Med education. 2017:17(1):1-7.

32. Kotrlik J, Higgins C. Organizational research: Determining appropriate sample size in survey research appropriate sample size in survey research. Information technology, learning, and performance journal 2001;19(1):43.

33. Taber KS. The use of Cronbach's alpha when developing and reporting research instruments in science education. Res Sci Educ. 2018;48(6):1273-96. https://doi.org/10.1007/s11165-016-9602-2.

34. Popping R. Analyzing open-ended questions by means of text analysis procedures. Bull Sociological Methodology/Bulletin de Méthodologie Sociologique. 2015;128(1):23-39. https://doi.org/10.1177/0759106315597389.

35. Lewis EF, Hardy M, Snaith B. Estimating the effect of nonresponse bias in a survey of hospital organizations. Eval Health Prof. 2013;36(3):330-51. https:// doi.org/10.1177/0163278713496565.

36. Lindner JR, Murphy TH, Briers GE. Handling nonresponse in social science research. J Agric Educ. 2001;42(4):43-53. https://doi.org/10.5032/jae.2001.04 043.

37. Hammoud MM, Foster LM, Cuddy MM, Swanson DB, Wallach PM. Medical student experiences with accessing and entering patient information in electronic health records during the obstetrics-gynecology clerkship. Obstet Gynecol. 2020;223(3):435. e1-6.

38. Wittels K, Wallenstein J, Patwari R, Patel S. Medical student documentation in the electronic medical record: patterns of use and barriers. Western Journal of Emergency Medicine. 2017;18(1):133-6. https://doi.org/10.5811/ westjem.2016.10.31294.

39. White J, Anthony D, WinklerPrins V, Roskos S. Electronic medical records, medical students, and ambulatory family physicians: a multi-institution study. Acad Med. 2017;92(10):1485-90. https://doi.org/10.1097/ACM. 0000000000001673.

40. Wang SJ, Middleton B, Prosser LA, Bardon CG, Spurr CD, Carchidi PJ, et al. A cost-benefit analysis of electronic medical records in primary care. Am J Med. 2003;1 14(5):397-403. https://doi.org/10.1016/S0002-9343(03)00057-3.

41. ACS. Statement on Medical Student Use of the Electronic Health Record. 2018; Available at: https://bulletin.facs.org/2018/04/statement-on-medicalstudent-use-of-the-electronic-health-record/, 2020.

42. Cheng DR, Scodellaro T, Uahwatanasakul W, South M. An electronic medical record in pediatric medical education: survey of medical Students' expectations and experiences. Applied Clin Informatics. 2018;9(4):809-16. https://doi.org/10.1055/s-0038-1675371.

43. Nulty DD. The adequacy of response rates to online and paper surveys: what can be done? Assess Eval High Educ. 2008;33(3):301-14. https://doi. org/10.1080/02602930701293231.

\section{Publisher's Note}

Springer Nature remains neutral with regard to jurisdictional claims in published maps and institutional affiliations.

\section{Ready to submit your research? Choose BMC and benefit from:}

- fast, convenient online submission

- thorough peer review by experienced researchers in your field

- rapid publication on acceptance

- support for research data, including large and complex data types

- gold Open Access which fosters wider collaboration and increased citations

- maximum visibility for your research: over $100 \mathrm{M}$ website views per year

At $\mathrm{BMC}$, research is always in progress.

Learn more biomedcentral.com/submission 